\title{
DETECCIÓN DE Pseudomonas spp. EN LA BAHÍA DE CARTAGENA
}

\author{
DETECTION OF Pseudomonas spp. IN THE BAY OF CARTAGENA
}

Roger-Alberto Rabelo-Florez * (D); Bernarda-Soraya Cuadrado-Cano² (D); Marco-Antonio MárquezGómez $^{3}$ (D); Jose-Ramiro Quintero-Caviedes ${ }^{1}$ (D); Darwin De La Rosa-Martínez ${ }^{1}$

1.Universidad Nacional Abierta y a Distancia, Cartagena, Bolívar, Colombia.

2. Universidad de Cartagena, Cartagena, Bolivar, Colombia

3. Universidad Nacional Abierta y a Distancia, Ocaña, Norte de Santander, Colombia.

*Correspondencia del Autor: Roger-Alberto Rabelo-Florez, correo electrónico: roger.rabelo@unad.edu.co Telefono celular: 3165322055

\section{RESUMEN}

Objetivo: El objetivo principal de esta investigación es obtener bacterias del género Pseudomona spp. con capacidad biodegradora de hidrocarburos en muestras de agua superficial de la Bahía de Cartagena de Indias. Material y Método: Diseño observacional, descriptivo, transversal y prospectivo. Se tomaron tres muestras de agua superficial de la Bahía de Cartagena de indias, se sembraron para preadaptacion y adaptación biológica de las bacterias en medio con sales minerales, ACPM 1\% v/v y petróleo crudo $1 \% \mathrm{v} / \mathrm{v}$, como única fuente de carbono y energía. Resultados: Las bacterias que crecieron en los medios con petróleo crudo fueron identificadas en 31 morfotipos de colonias bacterianas, de las cuales solo el 19,4\% dio positivo para la presencia de Pseudomona spp., y el 80,6\% restante, pertenecientes a otros grupos bacterianos. Discusión: Se evidenció un cambio de color en el agar nutritivo durante el procedimiento de aislamiento de las bacterias de la muestra 2 relacionado con la presencia de especies de Pseudomonas en especial P. aeruginosa. Conclusión: Se reporta la presencia del género de Pseudomona spp. con capacidad biodegradadora de petróleo en una de las muestras de agua recolectadas en la Bahía de Cartagena. Este estudio abre la posibilidad de futuros trabajos de bioprospección e identificación metabólica de las cepas aisladas.

Palabras clave: Adaptación biológica; petróleo; pseudomonas.

Cómo citar:

Rabelo-Florez, Roger-Alberto; Cuadrado-Cano, Bernarda-Soraya; Márquez-Gómez, Marco-Antonio; Quintero-Caviedes, Jose-Ramiro; De La Rosa-Martínez, Darwin. (2020) DETECCIÓN DE Pseudomonas SPP. EN LA BAHÍA DE CARTAGENA. Revista de Investigaciones Universidad del Quindio, 32(1), 30-41. https://doi.org/10.33975/riuq.vol32n1.293 


\begin{abstract}
Objective: The main objective of this research is to obtain bacteria of the genus Pseudomona spp. with biodegrading capacity of hydrocarbons in surface water samples from the Bay of Cartagena de Indias. Material and Method: Observational, descriptive, cross-sectional and prospective design. Three samples of surface water were taken from the Bay of Cartagena de Indias, they were sown for pre-adaptation and biological adaptation of the bacteria in a medium with mineral salts, ACPM 1\% v/v and crude oil 1\% v/v, as the only carbon source. and energy. Results: The bacteria that grew in the media with crude oil were identified in 31 morphotypes of bacterial colonies, of which only 19.4\% were positive for the presence of Pseudomona spp., And the remaining 80.6\%, belonging to other bacterial groups. Discussion: A color change in the nutrient agar was evidenced during the isolation procedure of the bacteria from sample 2 related to the presence of Pseudomonas species, especially $P$. aeruginosa. Conclusion: The presence of the genus of Pseudomona spp. with oil biodegrading capacity in one of the water samples collected in the Bay of Cartagena. This study opens the possibility of future work on bioprospecting and metabolic identification of the isolated strains.
\end{abstract}

Keywords: Biological adaptation; petroleum; pseudomonas.

\section{INTRODUCIÓN}

La contaminación por hidrocarburos del petróleo es un problema de carácter mundial y amplia distribución geográfica, teniendo en cuenta que independiente de la zona afectada, ya sea por procesos biológicos y físicos, tienen como destino final los mares y océanos (Carpenter, 2019; Diez et al., 2019). Los derrames accidentales o provocados, afectan tanto el suelo como el agua, así como también causan una alteración a la calidad del paisaje (Serrano et al., 2013) y en la producción agrícola (Odukoya et al., 2019). En Cartagena de Indias, la calidad de las aguas costeras se ha visto alterada por los efluentes domésticos, industriales y agrícolas, como por el transporte terrestre, fluvial y marítimo y por las descargas de la industria del petróleo (Echeverri et al., 2010; Eljaiek-Urzola et al., 2019).

La bahía de Cartagena se encuentra rodeada por islas que forman conjuntamente canales naturales, permitiendo así una comunicación directa entre la bahía y el mar Caribe y la renovación periódica de sus aguas (Cogua et al., 2012; Tosic et al., 2017). Además, se ven afectados a causa de los derrames de compuestos químicos derivados del petróleo, los sistemas de producción, la salud, la economía y las formas de vida de las poblaciones, debido a los efectos (mutagénicos y carcinogénicos) en los seres humanos y para los demás seres vivos (Cavazos et al., 2014; Tosic, et al., 2017).
En ecosistemas que han sido alterados por derrames accidentales o provocados de petróleo o sus derivados, se han identificado procariotes que han logrado sobrevivir a esas condiciones medioambientales adversas y reciben el nombre de bacterias nativas biodegradadoras de hidrocarburos y cuya presencia y aprovechamiento gana importancia día a día, dentro de las cuales se pueden mencionar especies del género Pseudomonas (Wu et al, 2018). Es por ello, que el objetivo del presente estudio es obtener bacterias del género Pseudomona spp. con capacidad biodegradora de hidrocarburos, a partir de muestras de agua superficial, extraidas de los cuerpos de agua de la Bahía de Cartagena de Indias.

\section{METODOLOGÍA}

Diseño del estudio: Observacional descriptivo, transversal y prospectivo.

\section{Area de estudio}

El procedimiento de muestro se realizó según el Standard Methods 2012 edición 22, APHA et al., (2012). Las muestras de agua se tomaron en septiembre de 2019, en la Bahía de Cartagena de indias en el sector Barrio Albornoz, ya que esta zona es de acceso libre en inmediaciones del vertimiento final de una industria petroquímica, en los siguientes puntos: Muestra 1: $10^{\circ} 22^{\prime} 06.8^{\prime \prime} \mathrm{N}$ $75^{\circ} 30^{\prime} 31.3^{\prime \prime} \mathrm{W}, \quad$ Muestra 2: $10^{\circ} 22^{\prime} 06.9^{\prime \prime} \mathrm{N}$ $75^{\circ} 30^{\prime} 31.3$ ”W, Muestra 3: $10^{\circ} 22^{\prime} 06.7^{\prime \prime} \mathrm{N}$ 
$75^{\circ} 30^{\prime} 31.3^{\prime \prime} \mathrm{W}$, siendo transportadas previa rotulación (Echeverri et al., 2010; DES, 2018) bajo condiciones de refrigeración, para su procesamiento en el laboratorio de Microbiología de la Universidad Nacional Abierta y a Distancia UNAD CCAV Cartagena.

\section{Procesamiento de la muestra y análisis micro- biológico.}

Las muestras fueron procesadas en dos fases, 1) preadaptación biológica y 2) adaptación biológica de las bacterias, siguiendo los protocolos publicados (Narváez et al., 2008; Samanez, 2008 y Echeverri et al., 2010), con algunas modificaciones.

Fase de preadaptación biológica. Se realizó bioestimulación la cual consiste en promover la proliferación de microorganismos nativos del medio contaminado mediante la adición de nutrientes (Reyes-Reyes et al., 2018). Para ello, de cada muestra se prepararon diluciones $1 / 10$ con caldo de preadaptación $\left(\mathrm{NH}_{4}\right) \mathrm{H}_{2} \mathrm{PO}_{4}$ (MAP) (modificado de Narváez et al., 2008) con ACPM al $1 \% \mathrm{v} / \mathrm{v}$ suministrado por una bomba de gasolina de la ciudad de Cartagena e incubando a $35^{\circ} \mathrm{C}$ con agitación permanente, durante siete días utilizando una plancha magnética de calentamiento a $35^{\circ} \mathrm{C}$, con termómetro para medición de temperatura (Echeverri et al., 2010; Narváez et al., 2008).

Fase de adaptación biológica. Se estimuló el crecimiento microbiano tomando un mililitro de caldo de preadaptación, para hacer una dilución $1 / 10$ con caldo medio mínimo de sales con petróleo crudo al $1 \% \mathrm{v} / \mathrm{v}$, en un tubo de ensayo tapa rosca. El caldo enriquecido, se preparó con sales grado reactivo, $\mathrm{K}_{2} \mathrm{HPO}_{4}: 1.5 \mathrm{~g} / \mathrm{L} ; \mathrm{KH}-$ ${ }_{2} \mathrm{PO}_{4}: 0.5 \mathrm{~g} / \mathrm{L} ;\left(\mathrm{NH}_{4}\right) 2 \mathrm{SO}_{4}: 0.5 \mathrm{~g} / \mathrm{L} ; \mathrm{NaCl}: 0.5 \mathrm{~g} / \mathrm{L}$; $\mathrm{FeSO}_{4}: 0.002 \mathrm{~g} / \mathrm{L}$, (modificado de Echeverri et al., 2010; y Narváez et al., 2008) mezclado con $1000 \mathrm{~mL}$ de agua destilada y suplementado con petróleo crudo al $1 \% \mathrm{v} / \mathrm{v}$. El petróleo crudo fue suministrado por el laboratorio de Microbiología del CCAV Cartagena - UNAD. Las muestras fue- ron incubadas a $35^{\circ} \mathrm{C}$ por siete días empleando una plancha magnética de calentamiento a $35^{\circ} \mathrm{C}$, con agitación magnética y verificación de la temperatura mediante el uso de un termómetro de mercurio (Echeverri et al., 2010; Narváez et al., 2008).

Selección de cepas. Una vez cumplido el tiempo de la fase de adaptación biológica de siete días, se tomaron $10 \mu \mathrm{L}$ del caldo medio mínimo de sales con crecimiento y se sembraron por superficie con ayuda de un asa de Drigalsky en placas de agar nutritivo (Scharlab®) suplementadas con $1 \% \mathrm{v} / \mathrm{v}$ de petróleo crudo, incubándose a $35^{\circ} \mathrm{C}$ (Narváez et al., 2008). Se seleccionaron las colonias más representativas y de mejor crecimiento, de estas, un total de 31 colonias fueron sembradas por agotamiento en agar nutritivo e incubadas a $35^{\circ} \mathrm{C}$ durante 48 horas. Luego, se procedió realizar la descripción de los morfotipos de las colonias y la coloración de gram, para visualizar la morfología microscopica se usó del microscopio compuesto con el objetivo de 100X (Murray et al., 2014 y Čepl et al., 2016).

Las colonias de bacterias gram negativas según la coloración de Gram, fueron sembradas en agar base según King (Merck $\left.{ }^{\circledR}\right)$, para aislamiento selectivo de bacterias pertenecientes al género Pseudomona spp., siendo consideradas pertenecientes a este género, aquellas colonias que cambiaron el medio a color amarillo verdoso.

Análisis estadístico: Con la información recolectada se construyó una base de datos en Excel bajo Windows, posteriormente se realizó un análisis descriptivo y univariado, presentando las variables cualitativas en proporciones y números absolutos. Se compararon los aislamientos con los resultados en la tinción de Gram, las características morfotípicas, microscópicas y la identificación presuntiva lograda con el medio en agar B (Base) según King, por medio de la prueba Chi cuadrado $\left(X^{2}\right)$ o exacta de Fischer. Los valores de p menor a 0,05 fueron considerados como indicador de significancia estadística. Todos los análisis estadísticos se realizaron por medio del software 
IBM SPSS Statistics versión 22.0.

\section{RESULTADOS}

Fase de preadaptación biológica: Luego de los siete días en incubación a $35^{\circ} \mathrm{C}$ se observó cambio de color en el caldo de cultivo en los tubos, pasando estos de cristalino a turbio y con mayor pérdida de la transparencia en las muestras 1 y 3 , con respecto a la muestra 2 (Figura 1).

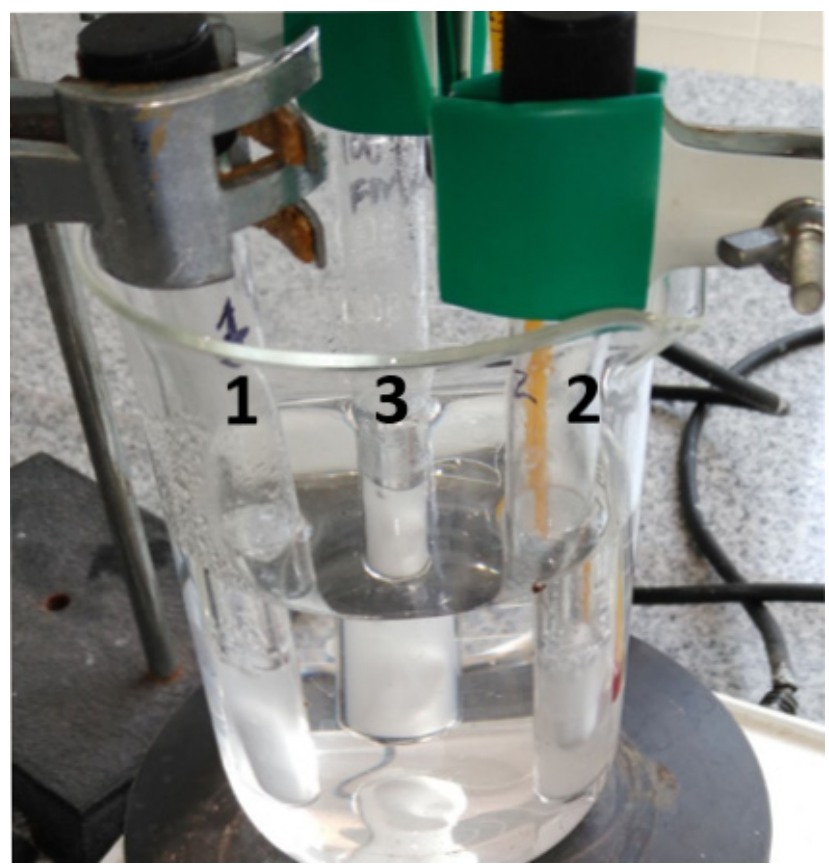

Figura 1. Tubos con caldo de MAP con ACPM al 1\% v/v y muestras de agua
Fase de adaptación biológica. A los siete días de incubación se observó en todos los tubos con caldo medio mínimo de sales con petróleo crudo al $1 \% \mathrm{v} / \mathrm{v}$, cambio de color, apreciándose en las muestras 1 y 2 mayor turbidez y aparición de un color café claro, con respecto a la muestra 3 (Figura 2).

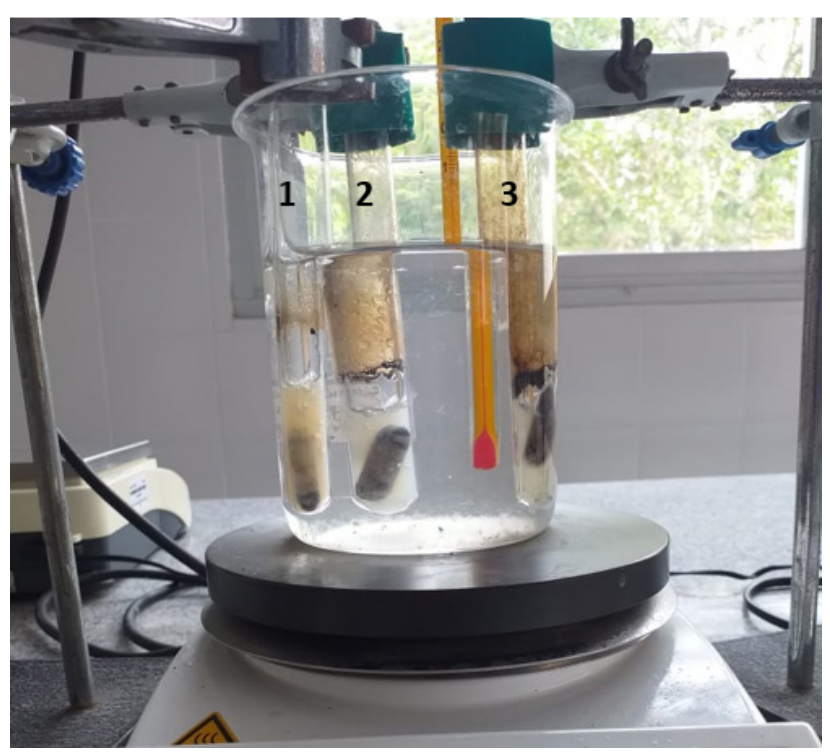

Figura 2. Tubos con caldo Medio Mínimo de sales y Petróleo crudo $1 \% \mathrm{v} / \mathrm{v}$ y muestras de agua

Morfotipos. Terminado el tiempo de incubación a $35^{\circ} \mathrm{C}$ durante 72 horas, se observó que sobre el agar nutritivo al $1 \% \mathrm{p} / \mathrm{v}$ de petróleo crudo cre-

cieron colonias que generaron desaparición parcial de la coloración oscura del crudo de petróleo, produciendo colonias translúcidas (Figura 3).
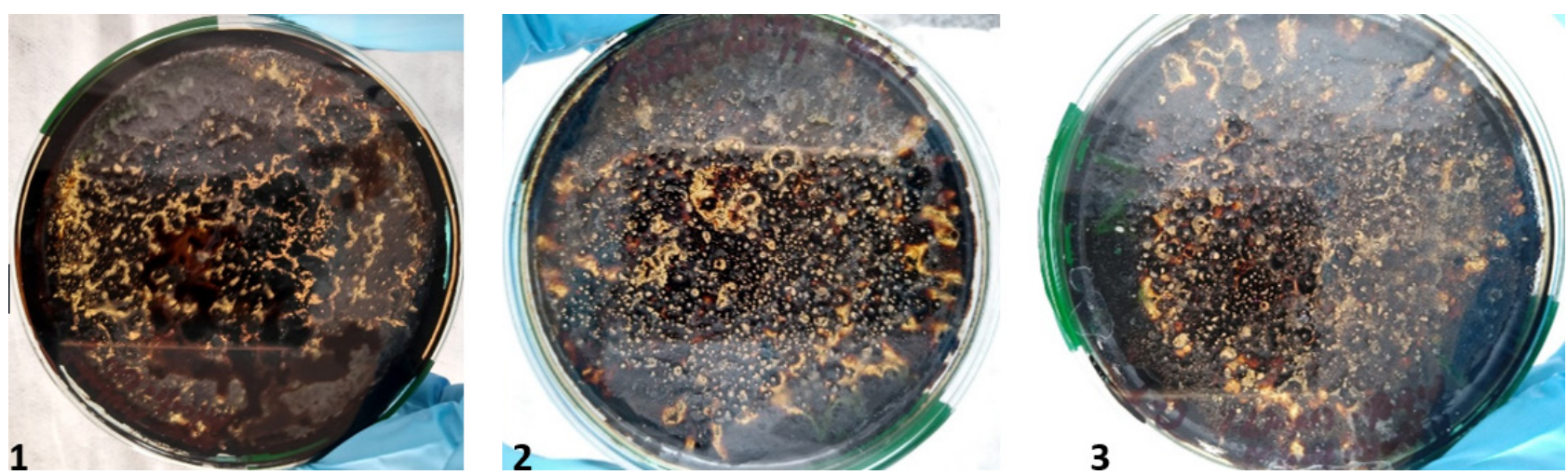

Figura 3. Colonias en agar nutritivo con petróleo crudo al $1 \%$ p/v obtenidas de las tres muestras de agua 
De las colonias sembradas por aislamiento en agar nutritivo (Figura 4), de las tres muestras, solo las de la muestra 2 produjeron un cambio en el color ambar normal del medio de cultivo hacia uno ligeramente ocre.

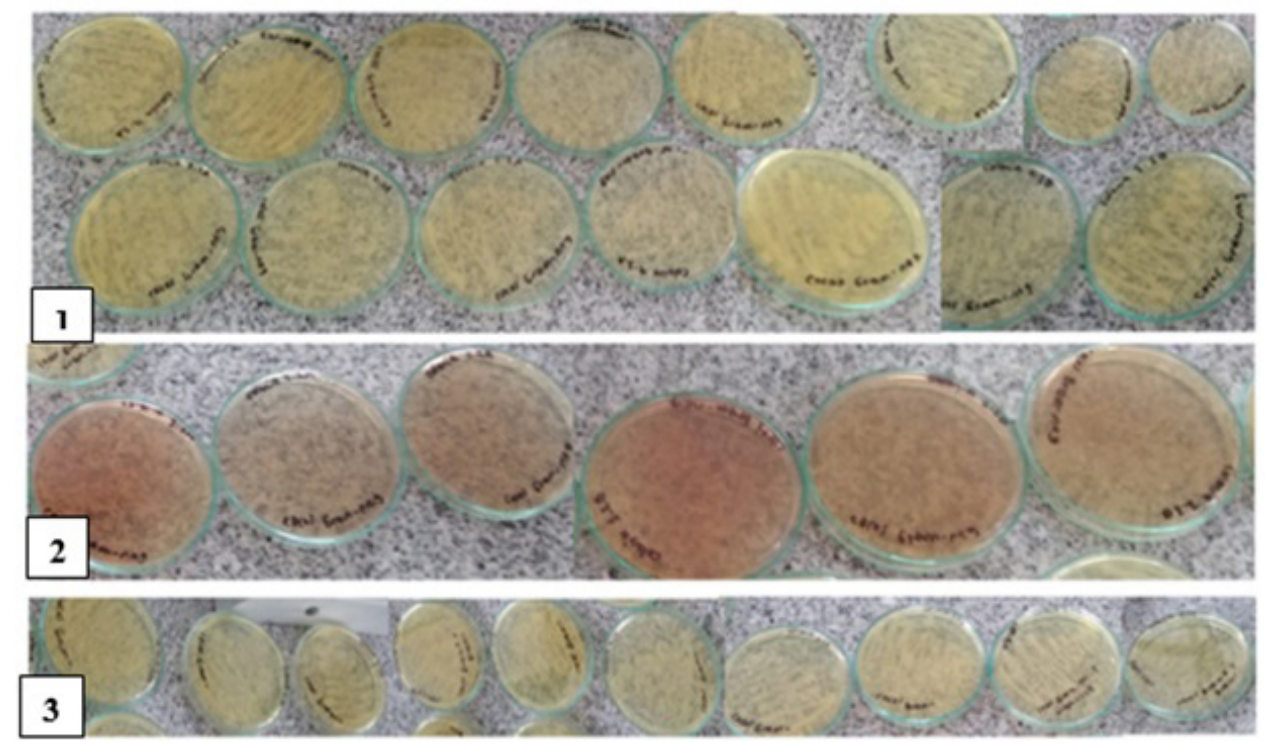

Figura 4. Agar nutritivo con morfotipos bacterianos de las tres muestras de agua. 1) Muestra 1,2) Muestra 2 con cambios de color del medio de cultivo y 3 ) Muestra 3

Dependiendo de la muestra, se lograron sembrar de la número 1,15 colonias $(48,4 \%)$, de la 2,6 $(19,4 \%)$ y de la 3, $10(32,3 \%)$. En el agar nutritivo se observó que todas las colonias mantuvieron el tamaño previo en el agar nutritivo con petróleo crudo al 1\% siendo consideradas como grandes (Figura 4). La forma más frecuente fue la de tipo irregular (81\%); y según el tipo de borde, el que predominó fue el lobulado (74\%) seguido del ondulado (16\%). En cuanto a la elevación la de mayor frecuencia fue la de tipo convexa $(77 \%)$ y la plana (23\%); por otro lado, la superficie que más abundó fue la lisa (61\%) seguida de la rugosa $(39 \%)$. La consistencia que predominó, fue la dura $(52 \%)$, siendo el resto blanda $(29 \%)$ y mucoide $(19 \%)$, mientras que el aspecto de mayor frecuencia fue la brillante $(81 \%)$, seguida de la opaca $(19 \%)$. Con relación al color, predominó el beige $(58 \%)$, seguido del ocre $(23 \%)$ y en trecer lugar, el translucido (19\%) (Tabla 1).

Tabla 1. Características morfológicas de las 31 colonias aisladas a partir de agar Agar nutritivo con petróleo crudo al

\begin{tabular}{ccc|ccc|cccc}
\hline Morfotipo & \multicolumn{2}{c|}{ Forma } & \multicolumn{3}{c|}{ Borde } & \multicolumn{2}{c}{ Elevación } & Superficie \\
\hline Tipo de Morfotipos & Circular & Irregular & Continuo & Ondulado & Lobulado & Plana & Convexa & Rugosa & Lisa \\
\hline Cantidad Morfotipos & 6 & 25 & 3 & 5 & 23 & 7 & 24 & 12 & 19 \\
Porcentaje \% & $\mathbf{1 9}$ & $\mathbf{8 1}$ & $\mathbf{1 0}$ & $\mathbf{1 6}$ & $\mathbf{7 4}$ & $\mathbf{2 3}$ & $\mathbf{7 7}$ & $\mathbf{3 9}$ & $\mathbf{6 1}$ \\
\hline Total Morfitipos & & & & & 31 & & 31 & 31 \\
\hline
\end{tabular}

\begin{tabular}{cccc|cc|ccc}
\hline Morfotipo & \multicolumn{3}{c|}{ Consistencia } & \multicolumn{2}{c|}{ Aspecto } & \multicolumn{3}{c}{ Color } \\
\hline Tipo de Morfotipos & Blanda & Dura & Mucoide & Opaca & Brillante & Translucido & Ocre & Beige \\
\hline Cantidad Morfotipos & 9 & 16 & 6 & 6 & 25 & 6 & 7 & 18 \\
Porcentaje \% & $\mathbf{2 9}$ & $\mathbf{5 2}$ & $\mathbf{1 9}$ & $\mathbf{1 9}$ & $\mathbf{8 1}$ & $\mathbf{1 9}$ & $\mathbf{2 3}$ & $\mathbf{5 8}$ \\
\hline Total Morfitipos & & 31 & & 31 & 31 \\
\hline
\end{tabular}


Observación microscópica. En la tinción de Gram realizada a las 31 colonias se identifica en su mayoría gram negativos $(90,3 \%)$ y unos pocos Gram positivos (9,7\%), de los cuales, el 71,7\% son cocos gram negativos, $19,4 \%$ bacilos gram negativos y $9,7 \%$ cocos gram positivos (Tabla 2).

En la muestra 1, la totalidad de las 15 colonias que se aislaron correspondieron a cocos gram negativos, mientras que en la muestra 2, las 6 eran bacilos gram negativos y en la muestra 3 , de las 10 , el $70 \%$ a cocos gram negativos y el $30 \%$ a cocos gram positivos agrupados en sarcinas, cadenas tipo estreptococos y racimos tipo esta- filococos. Al comparar los aislamientos con los resultados en la tinción de gram, se presentaron diferencias estadísticamente significativas con $p$ $<0,05$.

Tabla 2. Características microscópicas de bacterias aisladas de agar nutritivo con petróleo crudo al $1 \% \mathrm{p} / \mathrm{v}$.

\begin{tabular}{ccccc}
\cline { 2 - 4 } & $\begin{array}{c}\text { Cocos } \\
\text { Gram } \\
\text { postivos }\end{array}$ & $\begin{array}{c}\text { Cocos } \\
\text { Gram } \\
\text { negativos }\end{array}$ & $\begin{array}{c}\text { Bacilos } \\
\text { Gram } \\
\text { negativos }\end{array}$ & Total \\
\hline $\begin{array}{c}\text { Forma y } \\
\text { Tinción de } \\
\text { Gram }\end{array}$ & 3 & 22 & 6 & $\mathbf{3 1}$ \\
\% Porcentaje & 10 & 71 & 19 & $\mathbf{1 0 0}$ \\
\hline
\end{tabular}

Identificación como Pseudomona spp. Unicamente las colonias de la muestra 2 y que presentaron cambios en el agar nutritivo, al ser sembradas en agar B (Base) según King, dieron lugar a un cambio del medio de ambar a color a verde amarillento, indicando la presencia de Pseudomonas spp. (Figura 5).

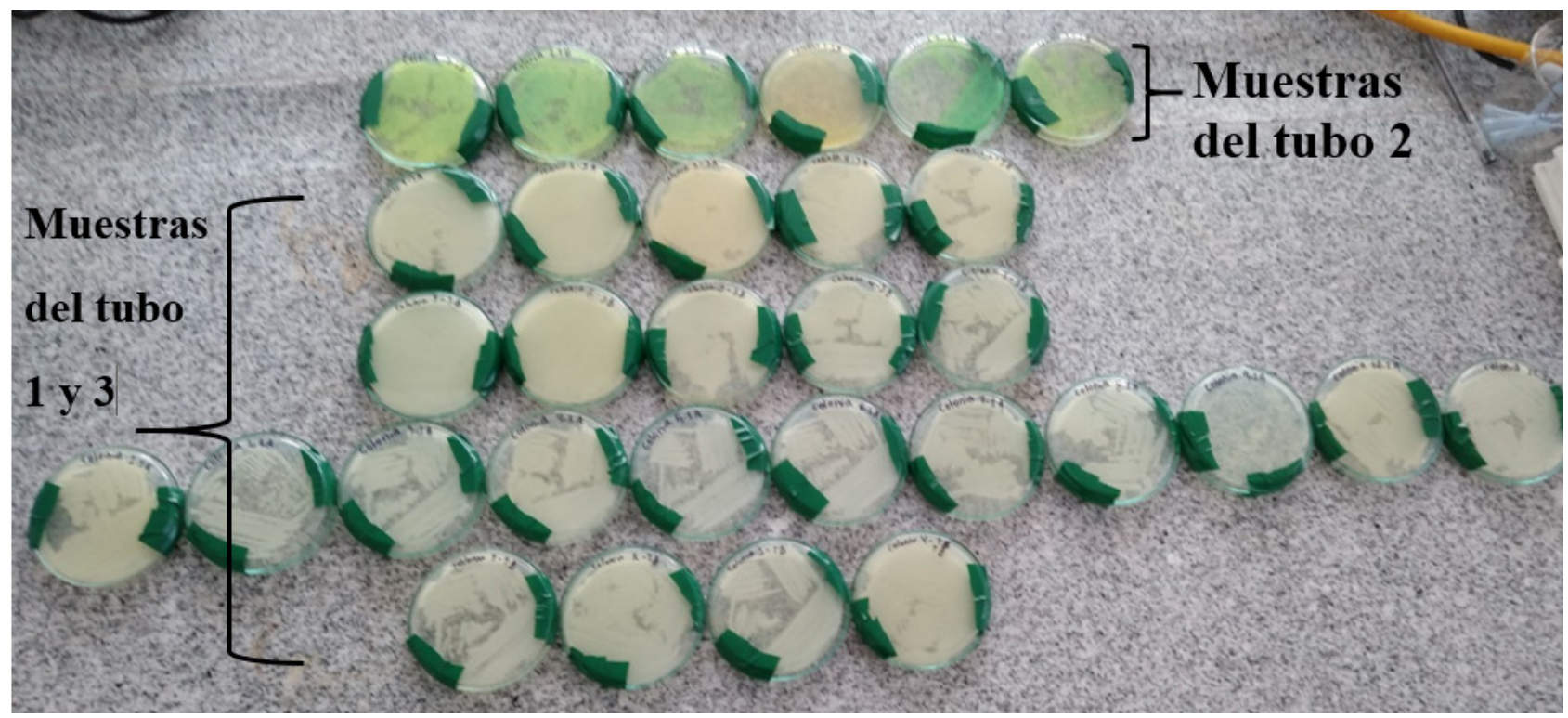

Figura 5. Cultivo de bacterias aisladas de las tres muestras de agua en agar Base según King

Las colonias identificadas como pertenecientes al género Pseudomonas desde el punto de vista de sus características morfotípicas y microscópicas son de tamaño grande, forma circular, borde lobulado, elevación convexa, superficie lisa, consistencia mucoide, aspecto brillante, color traslúcido y bacilos gram negativos, encontrándose diferencias estadísticamente significativas ( $p<0,05)$, entre las características morfotípicas y microscópicas y la identificación presuntiva lo- grada con el medio en agar B (Base) según King.

También se resalta que una de las cajas de la muestra del tubo 2, presentó mayor pigmentación verde, indicando la presencia presuntiva de $P s e u$ domona fluorescens y $P$. aeruginosa de acuerdo a las instrucciones de la casa comercial (Scharlab Grupo de Abastecimiento de Laboratorio, 2020 y Bio-Rad, 2020) (Figura 6), sin embargo se establece que aunque los demás morfotipos de la 
muestra 2, no presentaron mayor pigmentación verde, no significa que no sea posible la presencia de $P$. fluorescens y $P$. aeruginosa, debido a una baja producción de pioverdina.

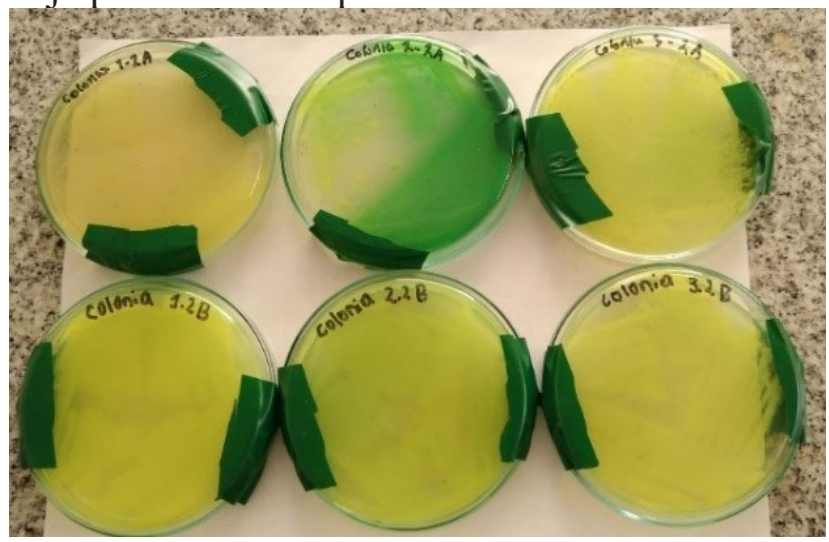

Figura 6. Cultivo de colonias de la muestra de agua 2 en agar Base según King con coloración verde amarillenta

\section{DISCUSIÓN}

Se identificó la presencia del género de Pseudomona spp. con capacidad biodegradadora de petróleo en una de las muestras de agua recolectadas en la Bahía de Cartagena.

En las fases de preadaptación biológica se observó que, mientras la muestra 2 no presentó casi crecimiento, determinado por la presencia de turbidez; en la fase de adaptación biológica, fue la única muestra donde las bacterias biodegradaron el petróleo casi en su totalidad, con resultados similares a los obtenidos en la muestra 1, presentándose disgregación del petróleo, situación acorde con lo registrado por (Echeverri et al., 2010 y Mwaura, 2017). Al pertenecer al género Pseudomona, se infiere que la vía utilizada para la biodegradación es la aerobia en especial porque los cultivos se dieron en agitación con aireación constante y además, porque según Madigan et al., (2015) y Brzeszcz y Kaszycki, (2018) en cuanto a la vía aeróbica, tanto los hidrocarburos alifáticos como los aromáticos, utilizan unas enzimas llamadas oxigenasas, que pueden ser monooxigenas y dioxigenesas, dando como resultado acetil-CoA en (HA), acetil-CoA, succinato y piruvato en (HAr), el cual se van a integrar en el ciclo de Krebs, causando aumento de la concentración microbiana y por ende aparición de turbi- dez en los cultivos (Salam et al., 2016).

Por otro lado, los resultados están de acuerdo con lo expresado por Ordoñez-Burbano et al., (2018), quien establece que las bacterias biodegradadoras logran tolerar elevadas concentraciones de hidrocarburos porque han desarrollado mecanismos para mantener la integridad de sus membranas, tales como el incremento en la rigidez de la membrana, por descenso en el contenido de ácidos grasos insaturados, la alteración en la conformación cis/trans de los fosfolípidos y la presencia de estructuras o enzimas capaces de metabolizar o degradar el contaminante, situación que se observó en especial con la muestra 2, que en la fase de preadaptación biológica aparentemente no creció, pero en la fase de adaptación biológica pudo lograr un buen desarrollo.

Es de resaltar que, mientras en la primera fase, la turbidez que adquirieron los cultivos fue blanquecina; en la segunda fase, la turbidez correspondió a un tono parduzco debido al disgregado del petróleo (Echeverri et al., 2010 y Mwaura, 2017). Además, aproximadamente, después del día siete de la primera fase, se logró observar la formación de un color amarillo en la superficie del caldo, por lo que se infiere en especial en la muestra 2 , es debido a la organización de una biopelícula ya sea por crecimiento microbiano reportado en especies de Pseudomona, por su metabolismo aerobio estricto oxidativo o por el acúmulo de metabolitos propios de la degradación del petróleo, situación que coincide con la investigación realizada por Lasa, (2005), en donde establece que, la etapa inicial del proceso de formación del biofilm es la adherencia sobre la superficie, proceso observado en las bacterias Gram negativas como la Pseudomonas aeruginosa y en donde según Lasa (2005), los flagelos cumplen un rol importante en la etapa de adherencia primaria, también que la motilidad, pareciendo que ayuda a la bacteria a alcanzar la superficie y contrarestar las repulsiones hidrofóbicas. De igual forma, en una investigación mas reciente Abadia et al., (2019), demostró que $P$. aeruginosa, tiene la capacidad de formación de biopelículas, lo que apoyarían los 
resultados obtenidos.

Es de anotar que en el agar nutritivo al 1\% p/v de petróleo, todas las colonias que crecieron sobre la superficie del medio eran translucidas y rodeadas de un halo del hidrocarburo, situación contraria a lo reportado por Echeverri et al., (2010), quienes describen colonias negras y puntiformes. Lo anterior hace pensar que dichos autores pudieron haber tomado como colonias, restos de petróleo sin biodegradar.

Por otro lado, el cambio de color evidenciado en el agar nutritivo durante el procedimiento de aislamiento de las bacterias de la muestra 2, no ha sido registrado en ninguno de los reportes relacionados con biodegradación de petróleo, pero si en las especies de Pseudomonas en especial P. aeruginosa, que produce piomelanina un pigmento de color café claro y que aumenta su síntesis con temperatura menor a 37 grados centígrados (Ausina y Moreno, 2005; Martínez, 2017), situación que ayuda a su identificación.

Llama la atención que las únicas bacterias que fueron bacilos gram negativos correspondieron a la muestra 2, y a su vez pertenecen al género Pseudomonas, lo cual está de acuerdo con lo reportado desde el punto de vista de la microscopía, ya que las bacterias Gram negativas, son las de mayor presencia en la biodegradación de hidrocarburos, en comparación con las bacterias Gram positivas. Esto se evidenció, en los estudios realizados por Napoles y Diaz (Napoles et al., 2019; Díaz et al., 2018), quienes emplearon un consorcio bacteriano integrado por bacterias Gram negativas: Xanthomonas sp., Acinetobacter bouvetii; Shewanella sp.; Defluvibacter lusatiensis, y Pseudomona spp, entre otras, para biodegradar hidrocarburos presentes en agua de mar, creciendo el medio de cultivo agarizado como colonias amarillas, amarillas - anaranjadas, blanco amarillentas, con bordes lisos, de tamaño mediano y grandes, redondas, brillantes, poco elevadas, abultadas, cremosas y opacas. De igual manera, Nisperuza y Montiel (2018), a partir de muestras del pozo petrolero, lograron la identifi- cación bioquímica de 40 cepas bacterianas que correspondían a 6 géneros de bacilos Gram negativos: Pseudomona, Burkholderia, Klebsiella, Acinetobacter, Enterobacter y Citrobacter. En otro estudio similar realizado por Largo (2011), utilizaron la bacteria Gram negativa Alcanivorax venutensis, para biodegradar hidrocarburo tipo alcanos y, Pardo et al., (2017), a partir de aguas residuales de la industria de petróleo, aislaron e identificaron bacterias Gram negativas: Pseudomonas sp., Pseudomonas putida, Achromobacter sp. situación que comprueba la presencia del género Pseudomonas y su potencial biodegradador de hidrocarburos.

Por otro lado, otras publicaciones avalan los resultado del presente estudio ya que están de acuerdo con lo reportado por Mayz y Manzi, (2017) en donde el género Pseudomonas fue aislado e identificado de forma predominante en ecosistemas contaminados y con gran capacidad para biorremediar suelos y cuerpos de aguas. Mayz y Manzi (2017), evaluaron la actividad de Pseudomonas fluorescens, P. putida y P. aeruginosa, para biorremediar la rizosfera de una leguminosa de un suelo contaminado con hidrocarburos. De igual forma, en otras investigaciones (Acuña et al., 2010; Bacosa et al., 2018 y He et al., 2019), encontraron diferentes géneros de bacterias, entre ellos Pseudomonas spp. para biodegradar hidrocarburos. Cui et al., (2019), de manera similar, hallaron en muestras de agua recolectadas de los pozos de inyección y producción de pozos petroleros, bacterias del género Acinetobacter, Pseudomonas, Marinobacter, Klebsiella, Vibrio, Marinobacterium, Chromonhalobacter y Thioclava. Tambien, en el estudio realizado por García et al., (2019), emplearon un consorcio bacteriano integrado por Acinetobacter sp., Pseudomonas sp. y Mycobacterium sp, para biorremediar aguas servidas contaminadas con hidrocarburos, provenientes de un local de lavadora de carros.

En este estudio se evidenció que de las 31 colonias seleccionadas, solo el $19,4 \%$ dio positivo para la presencia de Pseudomona sp., mientras que el $80,6 \%$ a otros grupos bacterianos. Resul- 
tados acordes con las investigaciones realizadas por Gallegos et al., (2018) y Mayz y Manzi (2017), en donde predominó el género Pseudomonas sp., a lo largo de todas las fases de cultivo. Cui et al., (2019) y Pucci et al., (2015), encontraron que al inicio en las muestras tomadas de agua de pozos petroleros y muestras de sedimentos del tanque de almacenamientos de petróleo respectivamente, hubo predominio de este género, pero en las fases posteriores disminuyó el crecimiento de esta bacteria, situación en contraposición con lo obtenido en este estudio y que pudo deberse a las condiciones fisicoquímicas presentes en el sitio donde se tomaron las muestras y que no fueron evaluadas y que podrían explicar también, el porqué el porcentaje de Pseudomonas sp. en las muestras tomadas pudo no ser muy significativa.

La relación encontrada entre las similitudes de las colonias aisladas y sus características microscópicas y a la vez con el género Pseudomona sp., está en concordancia con lo reportado en los trabajos realizados por Narváez et al., (2008) y Echeverri et al., (2010). Sin embargo, en gran parte de los trabajos reportados aquí, no describen el número de colonias aisladas y su correspondiente característica morfológica. En cuanto al crecimiento de bacterias en medios que contenían petróleo crudo, es similar a lo reportado por Narváez et al., 2008; Echeverri et al., 2010; Liu J., et al., 2017 y He et al., 2019, donde hubo una adaptación biológica microbiana a la contaminación por hidrocarburos. Se reitera la presencia de la bacteria perteneciente al género Pseudomona, en los medios de cultivo de la muestra 2, sembradas en el agar Base según King, por presentar una coloración amarillo verdoso, indicando la producción del pigmento pioverdina en las bacterias del genero Pseudomona spp. (Ausina y Moreno, 2005).

Como limitaciones del presente estudio se pueden mencionar, la no identificación plenamente de la identidad de las bacterias del grupo Pseudomonas spp., además, no se identificaron las otras bacterias no Pseudomonas, tampoco se logró evaluar las rutas metabólicas de como las bac- teria pueden degradar hidrocarburos, así como establecer las características físicoquimicas del ambiente donde se recolectaron las muestras. Por otro lado, las bacterias de la muestra 2, no crecieron tanto en la fase de preadaptación biológica, como si lo hizo en la fase de adaptación biológica, quizás debido a que la muestra fue muy pequeña, o porque el género Pseudomona spp. tiene mas afinidad para biodegradar el petróleo que el ACPM; sin embargo, no hay que descartar otra hipótesis, en la fase de adaptación biológica el caldo medio mínimo de sales contenía mayor diversidad de sales, situación que le pudo brindar a los microorganismos una similar condición salina a la del mar, mientras que en la fase de preadadaptación biológica solo tenia un tipo de sal.

Se concluye que el género Pseudomona spp. se logró detectar en los cuerpos de agua de la Bahía de Cartagena y logró biodegradar tanto el hidrocarburo ACPM como petróleo crudo. El género Pseudomonas spp, se aisló en 6 colonias del total de 31 seleccionadas. Lo anterior evidencia que este genero de bacteria, mantiene la vigencia como biodegradadora de hidrocarburo.

Este resultado de investigación, tiene como fortaleza que es un punto de partida para seguir estudiando el género Pseudomona spp, como bacteria potencial biodegradadora de petróleo, y es por ello, que se sugiere investigar el porcentaje de biodegradación de hidrocarburos de este género en la bahía de Cartagena de Indias y cúal compuesto químico especifico derivado del petróleo es capaz de biodegradar mejor. Por otro lado, se hace necesario a futuro el investigar la capacidad de biodegradar estos compuestos químicos en condiciones anóxicas, en especial empleando aquellas bacterias que se aislaron y no caracterizadas como Pseudomonas spp.

\section{AGRADECIMIENTOS}

Los autores agradecen a la Universidad Nacional Abierta y a Distancia - UNAD, por su apoyo logístico y financiación de este proyecto, a través de las convocatorias internas de apoyo a 
grupos y semilleros de investigación. También, agradecen al líder zona caribe de los laboratorios el químico Andres Ariza Arnedo, por el apoyo en la organización de los materiales y reactivos en el laboratorio. También agradecen a la Universidad de Cartagena y en especial al grupo de Investigación en Microbiología y Sistemas Simbióticos por el apoyo en esta investigación, tanto en ejecu- ción como en la elaboración del manuscrito.

\section{CONFLICTO DE INTERESES}

Los autores declaran que no tienen conflictos de intereses con respecto al contenido del presente manuscrito.

\section{BIBLIOGRAFÍA}

1. Abadia, E., Rodríguez, O. y De La Cruz, A. (2019). Efectividad de la formación de biofilms por cepas de pseudomona y su capacidad de disminución de cloro y antagónica de bacterias coliformes. Revista de Iniciación Científica, 5, 74-78. https://doi.org/10.33412/rev-ric.v5.0.2389

2. Acuña, AP., Graciela, MMJ y Pucci O. (2010). Biodegradación de petróleo y sus derivados por la comunidad bacteriana en un suelo de la Patagonia Argentina. Revista de la Sociedad Venezolana de Microbiología, 30(1), 29-36. Disponible en: http://www.scielo.org.ve/scielo.php?script=sci_ arttext\&pid=S1315-25562010000100007\&lng=es\&tlng=es.

3. APHA, AWWA, WEF. (2012). Standard Methods for examination of water and wastewater. 22nd ed. Washington: American Public Health Association. 1360 pp. ISBN 978-087553-013-0

4. Ausina, RV. y Moreno, GS. (2005). Tratado de SEIMC de Enfermedades Infecciosas y Microbiología Clinica. Buenos Aires; Madrid: Panamericana.

5. Burbano, DEO., Medina, CAA., Tamayo, AE., Lasprilla, LMP., y Benítez, CN. (2018). Biodegradación de hidrocarburos alifáticos saturados por microorganismos aislados de suelo contaminado con derivados del petróleo. Revista de Ciencias, 22(2). https://dx.doi.org/10.25100/rc.v22i2.7917

6. Bio-Rad. (2020). Medio King B. Medio de diferenciación de Pseudomonas. Recuperado el 23 de mayo de 2020 de: http://www.bio-rad.com/webroot/web/pdf/inserts/CDG/es/55278_08_2009_ES.pdf

7. Bacosa, HP., Erdner, DL, Rosenheim, BE., Shetty, P., Seitz, KW., Baker, BJ., y Liu, Z. (2018). Hydrocarbon degradation and response of seafloor sediment bacterial community in the northern Gulf of Mexico to light Louisiana sweet crude oil. The ISME journal, 12(10), 2532-2543. https://doi. org/10.1038/s41396-018-0190-1

8. Brzeszcz, J., Kaszycki, P. (2018). Aerobic bacteria degrading both n-alkanes and aromatic hydrocarbons: an undervalued strategy for metabolic diversity and flexibility. Biodegradation, 29, 359-407. https://doi.org/10.1007/s10532-018-9837-x

9. Cavazos, AJ., Pérez, AB. y Mauricio, GA. (2014). Afectaciones y consecuencias de los derrames de hidrocarburos en suelos agrícolas de Acatzingo, Puebla, México. Agricultura, sociedagd y desarrollo, 11(4), 539-550. https://doi.org/10.22231/asyd.v11i4.16

10. Carpenter, A. (2019). Oil pollution in the North Sea: the impact of governance measures on oil pollution over several decades. Hydrobiologia , 845 (1), 109-127. https://doi.org/10.1007/s10750-018-3559-2

11. Cogua, P, Campos, CNH y Duque, G. (2012). Concentración de mercurio total y metilmercurio en sedimento y seston de la bahía de cartagena, caribe colombiano*. Boletín de Investigaciones Marinas y Costeras - INVEMAR, 41(2), 267-285. Disponible en: http://www.scielo.org.co/scielo.php?script=sci_ arttext\&pid=S0122-97612012000200002\&lng=en\&tlng=es.

12. Čepl, J., Blahůšková, A., Neubauer, Z., \& Markoš, A. (2016). Variations and heredity in bacterial colonies. Communicative \& Integrative Biology, 9(6), e1261228. https://doi.org/10.1080/19420889.201 6.1261228

13. Cui, K., Zhang, Z., Zhang Z., Sun, S., Li, H. y Fu, P. (2019). Stimulation of indigenous microbes by optimizing the water cut in low permeability reservoirs for green and enhanced oil recovery. Scientific reports, 9(1), 1-12. https://doi.org/10.1038/s41598-019-52330-2

14. DES. 2018. Monitoring and Sampling Manual: Environmental Protection (Water) Policy. Brisbane: Department of Environment and Science Government.

15. Díz, BLC., Leal, JCM., Díaz, DAA., Ferrer, SJC. y Avendaño, EDM. (2018). Consorcio microbiano autóctono para el tratamiento de aguas contaminadas con gasoil del puerto de Isla de Toas (Venezuela). Ciencia e Ingeniería Neogranadina, 28(2), 5-27. https://doi.org/10.18359/rcin.2792 
16. Diez, SM; Patil, PG., Morton, J., Rodriguez, DJ., Vanzella, A., Robin, D., Maes, T., Corbin, C. (2019). Marine Pollution in the Caribbean : Not a Minute to Waste (English). Washington, D.C. : World Bank Group. Disponible en: http://documents.worldbank.org/curated/en/482391554225185720/Marine-Pollution-in-the-Caribbean-Not-a-Minute-to-Waste

17. Echeverri, JG., Manjarrez, PG. y Cabrera, OM. (2010). Aislamiento de bacterias potencialmente degradadoras de petróleo en hábitats de ecosistemas costeros en la Bahía de Cartagena, Colombia. NOVA, 8(13), 76-86. https://doi.org/10.22490/24629448.441

18. Eljaiek-Urzola, M., Romero-Sierra, N., Segrera-Cabarcas, L., Valdelamar-Martínez, D., \& QuiñonesBolaños, É. (2019). Oil and Grease as a Water Quality Index Parameter for the Conservation of Marine Biota. Water, 11(4), 856. https://doi.org/10.3390/w11040856

19. García, J., Peñafiel, HD. y Rodríguez, R. (2019). Bioremediación de hidrocarburos en aguas residuales con cultivo mixto de microorganismos: caso Lubricadora Puyango. Enfoque UTE, 10(1), pp. 185 - 196. https://doi.org/10.29019/enfoqueute.v10n1.312

20. Gallegos, RM., Madera, SR., Castro, EG., Nájera, MM., Domínguez, LM., García, LE. y Vega, LA. (2018). Toxicokinetic and toxicodynamic symbiotic interactions among intestinal Pseudomonas degrading of hydrocarbons with its wild host fish Chirostoma jordani. Revista Internacional de Contaminación Ambiental, 34(4), 751-765. http://dx.doi.org/10.20937/RICA.2018.34.04.15

21. He, S., NiY., Lu, L., Chai, Q., Liu, H., y Yang, C. (2019). Enhanced biodegradation of n-hexane by Pseudomonas sp. strain NEE2. Scientific reports, 9(1), 1-9. https://doi.org/10.1038/s41598-019-526610

22. Largo, PE. (2011). Degradación de alcanos por células de alcanivorax venustensis inmovilizadas en hidrogeles adhesivos y biodegradables. Tesis de Doctorado en Ciencias. Universidad del país Vasco. 212 p. https://addi.ehu.es/handle/10810/12269

23. Lasa, I., Pozo, JL., Penadés, JR y Leiva, J. (2005). Biofilms bacterianos e infección. Anales del Sistema Sanitario de Navarra, 28(2), 163-175. Recuperado el 10 de mayo de 2020, de http://scielo.isciii.es/ scielo.php?script $=$ sci_arttext\&pid $=\mathrm{S} 1137-66272005000300002 \& \operatorname{lng}=\mathrm{es} \& \operatorname{lng}=\mathrm{es} \mid$

24. Liu, J., Techtmann, SM., Woo, HL., Ning, D., Fortney, JL., y Hazen, TC. (2017). Rapid response of eastern Mediterranean deep sea microbial communities to oil. Scientific reports, 7(1), 5762. https://doi. org/10.1038/s41598-017-05958-x

25. Madigan, MT., Martinko, JM., Bender, KS., Buckley, DH. y Stahl, DA. (2015). Biología de los microorganismos de Brock. Pearson Educación. 14a. edición

26. Martínez R. I. (2017). Papel de EF-Tu en la interacción de Pseudomonas aeruginosa con los queratinocitos humanos. Universidad de las Islas Baleares. Recuperado de: https://dspace.uib.es/xmlui/ handle/11201/2654

27. Murray, PR., Rosenthal, KS. y Pfaller, MA. (2014). Microbiología médica. (7ma edición). Elsevier Health Sciences.

28. Mayz, J., y Manzi, L. (2017). Bacterias hidrocarburoclásticas del género Pseudomonas en la rizosfera de Samanea saman (Jacq.) Merr. Revista Colombiana de Biotecnología, 19(1), 29-37. http://dx.doi. org/10.15446/rev.colomb.biote.v19n1.57408

29. Mwaura, AN. (2017). Screening, Isolation And Characterization Of Hydrocarbonoclastic Bacteria From Oil Contaminated Soils. Recuperado de: http://erepository.uonbi.ac.ke/handle/11295/101451

30. Napoles, AJ., Bahín, DL., Gutiérrez, RM., Del Toro, Á. y Abalos, RA. (2019). Degradación de diesel en agua de mar utilizando un consorcio bacteriano. Tecnología Química, 39(2), 403-420. Recuperado en 02 de diciembre de 2019, de http://scielo.sld.cu/scielo.php?script=sci_arttext\&pid=S2224$61852019000200403 \& \operatorname{lng}=$ es\&tlng=es.

31. Narváez, FSL., Gómez, M. y Martínez, MM. (2008). Selección de bacterias con capacidad degradadora de hidrocarburos aisladas a partir de sedimentos del caribe colombiano. Boletín de Investigaciones Marinas y Costeras - INVEMAR, 37(1), 61-75. https://doi.org/10.25268/bimc.invemar.2008.37.1.182

32. Nisperuza, VAK.y Montiel, AM. (2018). Caracterización y evaluación de cepas bacterianas nativas con capacidad hidrocarburolítica del pozo petrolero de San Sebastián, Lorica, Departamento De Córdoba (Doctoral dissertation). Disponible en: https://repositorio.unicordoba.edu.co/handle/123456789/969

33. Odukoya, J., Lambert, R. y Sakrabani, R. (2019). Comprensión de los impactos del petróleo crudo y sus tensiones abióticas inducidas en la producción agroalimentaria: una revisión. Horticulturae , 5 (2), 47. https://doi.org/10.3390/horticulturae5020047

34. Ordoñez-Burbano, DE., Abella-Medina, CA., Echeverry-Tamayo, A., Paz-Lasprilla, LM., y BenítezCampo, N. (2018). Biodegradación de hidrocarburos alifáticos saturados por microorganismos aisla- 
dos de suelo contaminado con derivados del petróleo. Revista de Ciencias, 22(2), 33-44. https://dx.doi. org/10.25100/rc.v22i2.7917

35. Pardo, DS., Rojas, TD., Roldan, F., Brandão, P., y Almansa, ME. (2017). Biodegradación de fenol en aguas tratadas de la industria petrolera para re-uso en cultivos agrícolas. Revista de Biología Tropical, 65(2), 685-699. http://dx.doi.org/10.15517/rbt.v65i2.23992

36. Pucci, GN., Acuña, ATN., Tiedemann, MC. y Pucci, OH. (2010). Diversidad de bacterias cultivables con capacidad de degradar hidrocarburos de la playa de Caleta Córdova, Argentina. Revista Peruana de Biología, 17(2), 237-244. http://www.scielo.org.pe/scielo.php?script=sci_arttext\&pid=S172799332010000200015\&lng=es\&tlng=es

37. Pucci, G., Acuña, A. y Pucci, O. (2015). Biodegradación de hidrocarburos en fondos de tanques de la industria petrolera. Revista peruana de biología, 22(1), 97-101. http://www.scielo.org.pe/scielo. php?script $=$ sci arttext\&pid=S1727-99332015000100006\&lng=es\&nrm=iso

38. Reyes-Reyes, MA., Puentes-Cala, EA., Casanova-Montes, EL., López-Deluque, F., Panqueva-Álvarez, JH. y Castillo-Villamizar, GA. (2018). Inmovilización de bacterias potencialmente degradadoras de petróleo crudo en matrices orgánicas naturales y sintéticas. Revista internacional de contaminación ambiental, 34(4), 597-609. https://doi.org/10.20937/rica.2018.34.04.04

39. Salam, L.B. (2016). Metabolism of waste engine oil by Pseudomonas species. 3 Biotech 6, 98. https:// doi.org/10.1007/s13205-016-0419-5

40. Samanez, GE. (2008). Biodegradación bacteriana por bio-estimulación en suelos contaminados con petróleo crudo. Universidad Nacional Mayor de San Marcos Facultad de Farmacia y Bioquímica. Lima - Perú. Disponible en: http://cybertesis.unmsm.edu.pe/bitstream/cybertesis/245/1/Samanez_ge.pdf

41. Scharlab, GAL. (2020). King B Agar (F Agar). Recuperado el 23 de mayo de 2020 de: https://scharlab. com/catalogo-productos-detalle-referencia.php? $\mathrm{r}=01-029-500 \& \mathrm{dw}=$ King-B-Agar-F-Agar-

42. Serrano, GMF., Torrado GLM. y Pérez RDD. (2013). Impacto de los derrames de crudo en las propiedades mecánicas de suelos arenosos. Revista Científica General José María Córdova, 11(12), 233-244. https://doi.org/10.21830/19006586.195

43. Tosic, M., Restrepo, J. D., Lonin, S., Izquierdo, A., \& Martins, F. (2019). Water and sediment quality in Cartagena Bay, Colombia: Seasonal variability and potential impacts of pollution. Estuarine, Coastal and Shelf Science, 216, 187-203. https://doi.org/10.1016/j.ecss.2017.08.013

44. Wu T, Xu J, Xie W, Yao Z, Yang H, Sun C and Li X (2018). Pseudomonas aeruginosa L10: A Hydrocarbon-Degrading, Biosurfactant-Producing, and Plant-Growth-Promoting Endophytic Bacterium Isolated From a Reed (Phragmites australis). Front. Microbiol. 9:1087. https://doi.org/10.3389/ fmicb.2018.01087 